\title{
Reconstruction of the state road D8 - comparison of the variant solutions
}

\author{
D. Cvitanić ${ }^{1}$, D. Breški ${ }^{1}$ \& I. Lovrić ${ }^{2}$ \\ ${ }^{I}$ Department of Transportation, Faculty of Civil Engineering and \\ Architecture, University of Split, Croatia \\ ${ }^{2}$ Department of Transportation, Faculty of Civil Engineering, \\ University of Mostar, Bosnia and Herzegovina
}

\begin{abstract}
Reconstruction of the state road D8, section Plano - Solin, has been proposed within the "Program of construction and maintenance of Croatian public roads". This road has been classified as a main road for fast-moving traffic. However, in the study "Physical planning with traffic analysis of state road D8, section Solin - Plano" it was proposed that the subject $9 \mathrm{~km}$ long four-lane road with a central reserve should be provided with eight traffic signal controlled at-grade intersections. As state roads by their basic function and under the Croatian Public road act are defined as "public roads, which connect the entire territory of the Republic of Croatia and provide connections with the network of main European roads", our opinion is that they should be connected only to county roads and main urban roads. In view of the existing traffic flows such connections should be made as grade-separated facilities. In this paper, besides comparison of resulting performance measures such as average delay and other, the cost-benefit analysis for the two variant solutions was performed.

Keywords: state road, signalized intersections, interchanges, construction costs, fuel consumption, cost benefit analysis, net present value.
\end{abstract}

\section{Introduction}

Reconstruction of the state road D8, section Plano - Solin, has been proposed within the "Program of construction and maintenance of Croatian public roads" [1]. This road has been classified as a main road for fast-moving traffic. The subject Plano-Solin section, which is the busiest route of state road D8, stretches 
from bypass road of the town of Trogir in the west to the bypass road of the town of Split on the east. According its location in the road network this road has a dual function. First, it is a connection to the northern part of Croatia (in the sense of receiving long distance and transit flows) and second it is a suburban road with a great number of origin and destination trips. After finishing the AdriaticIonian motorway this road would become exit/entrance of this area to the motorway.

According to the data from [2] on this road average annual daily traffic (AADT) in 2001 was 17774, and average summer daily traffic (ASDT) was 23611 vehicles. Volumes on the cross roads which intersect with subject section were substantially lower (about one tenth of the total traffic on the major road).

Currently, cross section of this road consists of one lane per direction without auxiliary turning lanes at the existing at grade unsignalized intersections. On this section five roads from town Kaštela as well as two county roads are connected. Because of poor geometry, quality of traffic flows on the intersections is low. A problem associated with vehicle delays on major road is caused by left turning vehicles onto the minor roads. Also, the minor road vehicle delays and queue lengths are unacceptable.

Because of low quality of traffic operation the reconstruction of this road has been proposed and designed [4] in 1992 as a four-lane facility with a central reserve providing access to the county roads by grade-separated junctions (diamond interchanges).

However, in year 2001, the Croatian Road Authority ordered a new physical plan. According the new plan the subject section (nine kilometers long four-lane road with a central reserve) should be provided with eight traffic signal controlled at-grade intersections. At the main road approaches the new plan assumed two through lanes and auxiliary right and left turning lanes.

The layout of subject section with proposed locations of intersections and connection on Adriatic-Ionian motorway is given in figure 1. Figure 2 show proposed at -grade intersection design.

As the state roads by their basic function and under the Public Road Act are defined as "public roads which connect the entire territory of the Republic of Croatia and provide connections with the network of main European roads", our opinion is that they should be connected only to the county roads and the urban freeways. According to the existing traffic flows, such connections should be made as grade-separated facilities. Also, the proposed solution for pedestrian flows along the carriageway is unsuitable in terms of safety.

The performed traffic study [3] did not offered an analysis of possible variant solutions for this extremely important road section, which is very surprising because before 15 years plans were made for construction of an additional carriageway to the north. The solution from year 1992 proposed construction of three diamond-type grade separated junctions. Other access from road network was designed only as right side entrance/exit ramps. This variant also assumed a grade-separated junction in Plano where the connection of subject road from the Prgomet junction on the Adriatic motorway is proposed. For these design 
solutions we have no remarks because, from the category of subject road and traffic volumes, the most suitable solution is construction of interchanges.

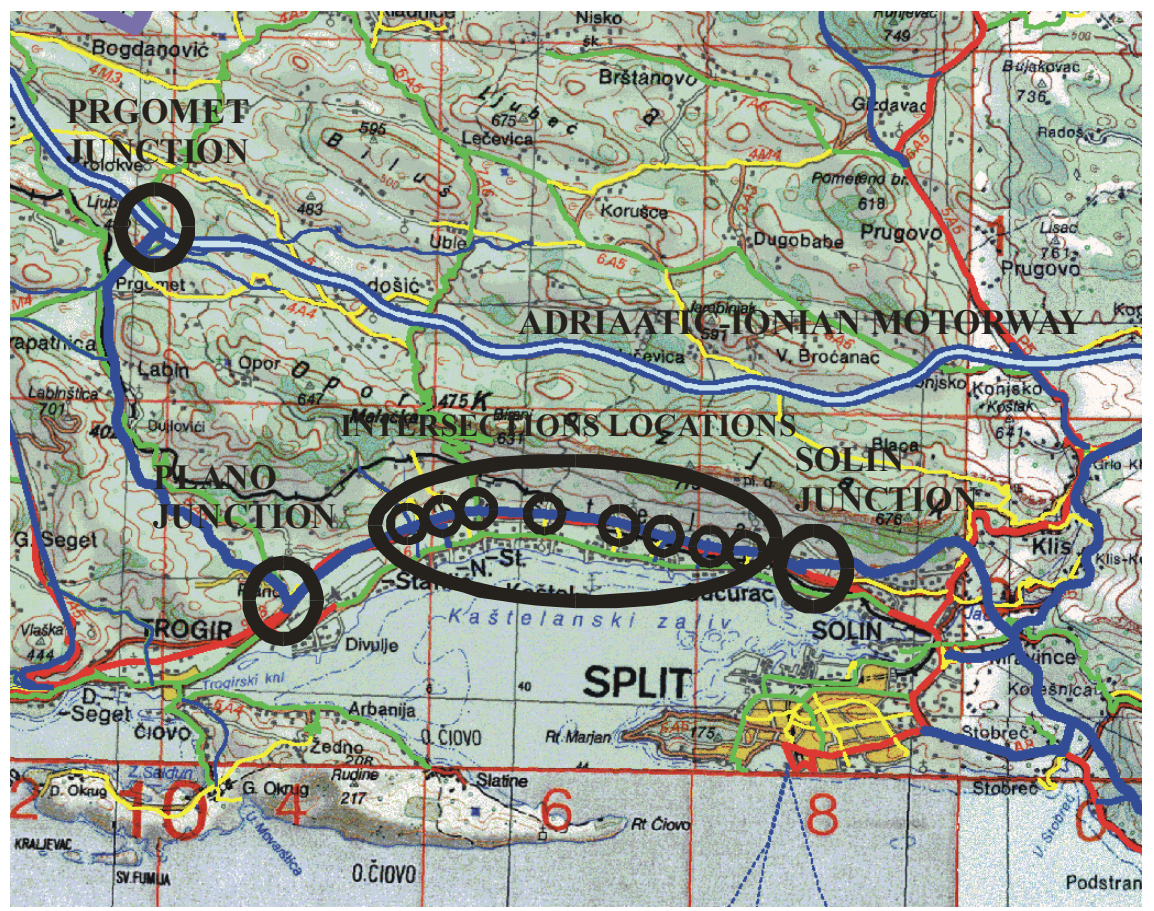

Figure 1: $\quad$ Proposed locations of at-grade intersections.

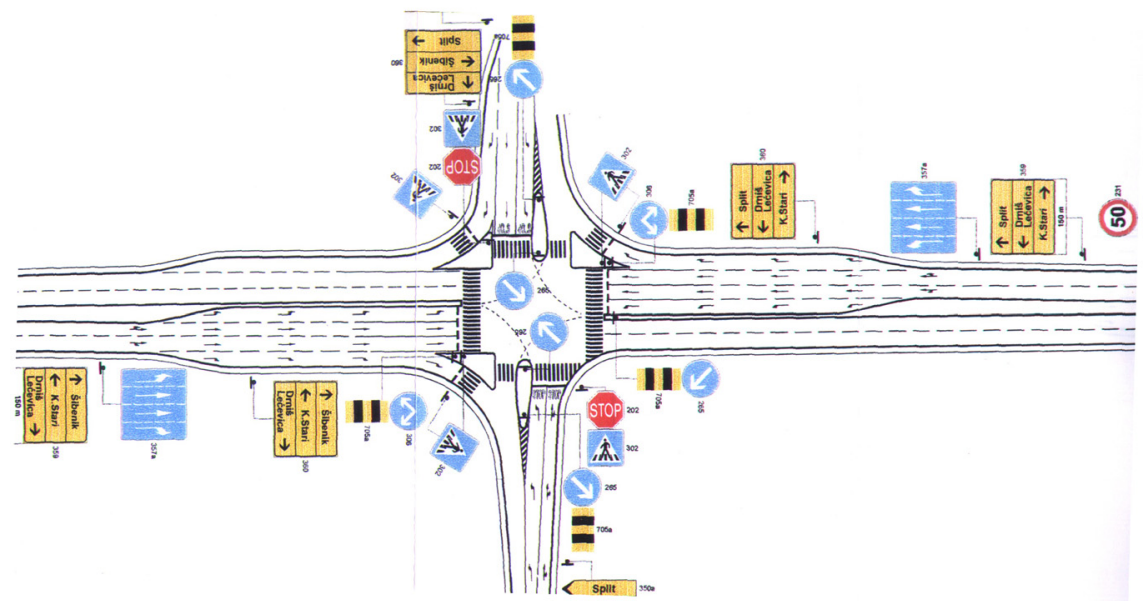

Figure 2: $\quad$ Proposed design of at grade intersections (year 2001). 
Even without conducting a detailed analysis of traffic flow operation, it is evident that the variant with at-grade intersections for this category of road and the existing traffic volumes is not the adequate solution.

Nevertheless, as guidance for making the final decision, here are compared two variant solutions in terms of the performance measures and related costs.

Variant I assume connection of the subject section to the road network over eight intersections with traffic signal. According to the Variant II there will be three diamond-type grade-separated junctions while other connections will be provided only as right turning exit/entrance ramps.

Besides the comparison of performance measures such as average delay, queue lengths and $\mathrm{v} / \mathrm{c}$, the cost-benefit analysis for the two variants has been performed for 20 years long period.

\section{Methodology and input data}

The input data to the traffic operation analysis are taken from [3]. According to traffic counts on the subject road section made in year 2002 the ADT was approximately 22,000 vehicles. Cross flows on minor roads entering the existing intersections ranged from 1,000 to a maximum of 4200 , the latter being recorded in Kaštel Stari where county road Ž6098 is linked to the subject state road. This county road leads to Split Airport to the south and Dalmatian hinderlands to the north. The existing AADT as well as the predicted volumes were applied in the computations. Value for peak hour flow of $8 \%$ was taken according to data from [5], while the directional split was assumed to be 55/45\%.

For the purpose of comparing the resulting performance measures of two variant solutions different methods were applied using different program packages. For comparison of the quality of traffic flows on the subject road section, regarding as a tangential artery provided with traffic signals on one side, and the suburban freeway provided with grade-separated junctions on the other side, the Artplan and Freeplan [6] computer programs were used. These programs are usually used for scheme planning and selection of the preferred option. The methodology applied in the analysis of traffic performance on the major route is based on HCM methodology [7], while that applied to evaluation of traffic flows quality on minor approaches is more simplified. The computations were made for separate segments of the subject route (open segments, junctions).

The basic inputs for computing performance measures on suburban "arteries" in the Artplan program were next: area in which the road is planned (transitioning/urban area), classes of the road (first class road assuming one traffic light per each $800 \mathrm{~m}$ and a minimum speed of $70 \mathrm{~km} / \mathrm{h}$ ), number of lanes on the major route, left turn lanes, type of central reserve, AADT, peak hour factor, directional split, proportion of heavy vehicles, proportion of additional lane uses, type of traffic control, posted speed. 


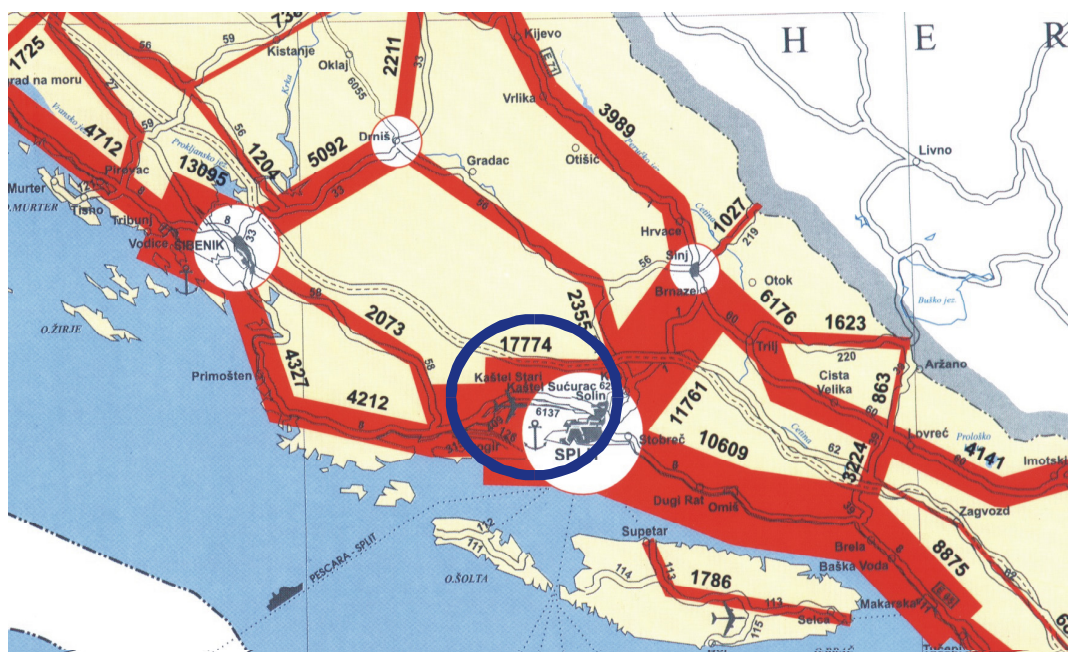

Figure 3: AADT record on the subject road section in year 2001 Croatian Road Authority Year Book "Traffic Counts on the Croatian Roads".

Particular input data are given for separate segments such are length of segment, travel time, relationship between effective times of green light and cycles, ADT, proportion of vehicles using auxiliary lanes, number of lanes per direction, flows from approaches and posted speed. The output data are degree of saturation between traffic flow and the capacity $(\mathrm{v} / \mathrm{c})$, delay, level of service, speed.

General input data for the Freeplan software are almost identical to those in Artplan. The particular inputs are the type (passing lanes or a particular type of grade-separated junction) and lengths of segments. The output data are degree of saturation $(\mathrm{v} / \mathrm{c})$, speed, density and the level of service per segment.

For easy comparison, in both programs the assumptions were made for a posted speed of $80 \mathrm{~km} / \mathrm{h}$, i.e. $88 \mathrm{~km} / \mathrm{h}$ of free flow speed.

The output results obtained by Artplan are shown in table 1. The outputs from Freeplan are shown in table 2. By comparing the results of the analysis it can be concluded that both solutions would operate satisfactory in the terms of traffic performance measures.

However, queuing at signalized intersections along this high-speed road causes an average delay of $8 \mathrm{sec} / \mathrm{veh}$ per intersection, i.e. the average speed would decrease by $15 \mathrm{~km} / \mathrm{h}$ in relation to the assumed free flow speed of 88 $\mathrm{km} / \mathrm{h}$. For the variant with grade separated junctions this decrease would be only $1.5 \mathrm{~km} / \mathrm{h}$.

Average delay on this section is more than one minute per vehicle and the total delay of all vehicles in a peak hour is above 30 hours or more than 300 hours per day for variant with signalized intersections. Besides, the level of service for pedestrian flows along the carriageway is unsuitable.

More detailed data on performance measures of traffic flows for the solution with signalized intersections are obtained with a computer program Synchro [8]. 
This program applies a percentile method but it also offers presentation of the results according to HCM. Input data for traffic signal controlled intersections are almost identical to those applied in HCM.

Table 1: $\quad$ Artplan results per segment and the entire road section.

\begin{tabular}{|c|c|c|c|c|c|c|}
\hline $\begin{array}{c}\text { Cross Street } \\
\text { Name }\end{array}$ & $\begin{array}{c}\text { Thru } \\
\text { Flow }\end{array}$ & $\mathbf{v} / \mathbf{c}$ & $\begin{array}{c}\text { Control } \\
\text { Delay }\end{array}$ & $\begin{array}{c}\text { Approach } \\
\text { LOS }\end{array}$ & $\begin{array}{c}\text { Speed } \\
(\mathbf{k m} / \mathbf{h})\end{array}$ & $\begin{array}{c}\text { Segment } \\
\text { LOS }\end{array}$ \\
\hline SUCURAC & 1040 & 0.49 & 8.09 & $\mathrm{~A}$ & 61 & $\mathrm{~B}$ \\
\hline TVORNICA & 1017 & 0.48 & 7.96 & $\mathrm{~A}$ & 75 & $\mathrm{~A}$ \\
\hline GOMILICA & 1056 & 0.5 & 8.13 & $\mathrm{~A}$ & 73 & $\mathrm{~A}$ \\
\hline KAMBELOVAC & 990 & 0.47 & 7.85 & $\mathrm{~A}$ & 77 & $\mathrm{~A}$ \\
\hline LUKSIC & 878 & 0.41 & 7.44 & $\mathrm{~A}$ & 77 & $\mathrm{~A}$ \\
\hline STARI & 836 & 0.39 & 7.30 & $\mathrm{~A}$ & 70 & $\mathrm{~A}$ \\
\hline STAFILIC & 750 & 0.35 & 7.02 & $\mathrm{~A}$ & 69 & $\mathrm{~A}$ \\
\hline RUDINE & 726 & 0.34 & 7.96 & $\mathrm{~A}$ & 69 & $\mathrm{~B}$ \\
\hline \hline \multicolumn{7}{|c|}{ Arterial Length } \\
\hline
\end{tabular}

Table 2: $\quad$ Freplan results.

\begin{tabular}{|l|l|l|l|}
\hline Density $($ vehs $/ \mathrm{km})$ & v/c & Speed $(\mathrm{km} / \mathrm{h})$ & LOS \\
\hline $\mathbf{6 . 8}$ & $\mathbf{0 . 2 8}$ & $\mathbf{8 6}$ & $\mathbf{A}$ \\
\hline
\end{tabular}

For the needs of this research, we defined the locations of the intersections on the subject road by importing into the Synchro a geodetic map in dxf format. Number of lanes and their uses were defined for each signalized intersection. Also were entered all traffic parameters and characteristics of road. Thereupon, the peak hourly flow was analyzed for semi-automatic type of signal control. Summary of the input data and the obtained results for variant with traffic signal controlled intersections can be found in Table 3 . The results of the analysis show that the average delay per vehicle (in relation to travel time of continuous flow on the major road) on the analyzed intersections ranged between 4 and 6 seconds.

Table 3: Summary of the results obtained by the use of the Synchro program.

\begin{tabular}{|c|c|c|c|c|c|c|c|c|c|}
\hline Segment & Length (m) & $\begin{array}{l}\text { ADT } \\
\text { (veh) }\end{array}$ & $\begin{array}{c}\text { Peak hour } \\
\text { traffic flows - } \\
\text { major } \\
\text { approaches } \\
\text { (veh/hour) }\end{array}$ & $\begin{array}{l}\text { Control } \\
\text { delay - } \\
\text { major } \\
\text { approaches } \\
\text { (sec) }\end{array}$ & $\begin{array}{c}\text { Total major } \\
\text { vehicle delay in } \\
\text { peak hour } \\
\text { (vehhour/hour) }\end{array}$ & $\begin{array}{l}\text { Control } \\
\text { delay - } \\
\text { minor } \\
\text { approaches } \\
\text { (sec) }\end{array}$ & $\begin{array}{l}\text { Control } \\
\text { delay- all } \\
\text { vehicles } \\
\text { (sek) }\end{array}$ & $\begin{array}{l}\text { Number of } \\
\text { stops-major } \\
\text { approaches }\end{array}$ & $\begin{array}{c}\text { Peak hour } \\
\text { fuel } \\
\text { consumption } \\
\text { (lhour) }\end{array}$ \\
\hline 1 & 600 & 25550 & 2057 & 5 & 2,86 & 17 & 6,2 & 952 & 143 \\
\hline 2 & 520 & 22300 & 1856 & 5 & 2,58 & 11 & 5,5 & 945 & 215 \\
\hline 3 & 1430 & 22550 & 1790 & 4,2 & 2,09 & 12 & 5 & 726 & 254 \\
\hline 4 & 1200 & 20200 & 1765 & 2 & 0,98 & 12 & 2,1 & 366 & 240 \\
\hline 5 & 1700 & 22050 & 1762 & 5,5 & 2,69 & 10 & 6 & 928 & 307 \\
\hline 6 & 1650 & 24500 & 1720 & 6 & 2,87 & 21 & 10 & 753 & 234 \\
\hline 7 & 800 & 17950 & 1426 & 5 & 1,98 & 9 & 5,6 & 710 & 146 \\
\hline 8 & 700 & 17400 & 1382 & 5,8 & 2,23 & 8,9 & 6,2 & 738 & 193 \\
\hline TOTAL & 8600 & & 13758 & 38,5 & 18,27 & 100,90 & 46,60 & 6118 & 1732 \\
\hline
\end{tabular}

The average delay per vehicle on the entire road section was 38.5 s. Total delay of all vehicles in the analyzed hour was 18.27 hours. Number of stopped 
vehicles in the peak hour was 6118 which means that almost half of vehicles on major road should stop at each intersection. Mention should be made that the effects of pedestrian flows, i.e. the losses thus incurred were not included in the computations.

At the first sight, the results of the analysis do not predict considerable losses. However, a cost benefit analysis of the variant solutions over the design period of 20 years (until 2024) described in the following chapter will be of great assistance in a selection process of optimal design solution.

\section{Cost-benefit analysis for the variants in the design period}

This chapter presents an approximate analysis of costs and benefits for the variant solutions over 20 years long period. The Synchro results were used in the analysis.

As mentioned, the peak hour traffic flow of $8 \%$ of the total daily traffic flow was assumed. For evaluation of incurred costs it is estimated that total daily losses would be ten times greater than the peak hour losses.

Performed analysis involved initial costs such as land price and construction costs, as well as the acquired benefits or savings in a terms of fuel consumption and time losses. This analysis did not take into account other costs such as management and maintenance costs, increased amortization costs of vehicles arising from stops, environmental pollution costs, road accident-related costs, etc. Such cost estimates would greatly increase differences in costs of two variants i.e. would favor the variant with grade-separated junctions.

The purpose of this research is to determine the optimal solution not only in terms of quality but also in cost savings. This simplified estimate of benefits, i.e. savings (in fuel consumption and time) and costs (land and construction) with a discount back to a present value year to obtain the net present value for the scheme could contribute to the final decision under the feasible alternatives.

\subsection{Comparison of the initial costs (construction cost and land price)}

Variant I propose the construction of eight signalized intersections.

Variant II assume construction of three diamond-type interchanges. Other existing intersections would be reconstructed so that only right turn entrances/exits would be provided from the town of Kaštela area. All other traffic would be carried over underpasses connected to the secondary road networks. The construction of grade-separated junctions requires building of ramps as well as overpasses and underpasses. It also requires a greater area than that necessary for the at-grade crossings.

As regards to the requirement for almost identical secondary road network under the two variants, the major difference in construction costs would result from the price of constructing the diamond-type grade-separated junctions and the price for the traffic signal controlled intersections.

Since the lengths of auxiliary lanes for left and right turns at the at-grade intersections are approximately equal to those of parallel entrance/exit lanes at diamond interchanges, the price of their construction is assumed to be the equal. 
Therefore, here is evaluated the construction price for exit/entrance ramps and underpasses which represent the major price difference of variant solutions.

According to the preliminary design [4] the average total length of all ramps at one diamond-type junction is about $1,000 \mathrm{~m}$. All minor roads pass below the major road and all ramps should be constructed in cuts. Assuming slopes of 1:1.5 in the cuts or fills of ramps along the carriageway and the required $5.5 \mathrm{~m}$ height of the underpasses, it follows that approximately $11,000 \mathrm{~m}^{3}$ of excavation is required. The average price of excavation and stabilization of slopes is estimated to be approximately 50000 euro per junction.

The average price of substructure and pavement of the ramps is estimated to be approximately 250000 euro. A standard-type underpass facility at a diamondtype junction requires an area of up to $500 \mathrm{~m}^{2}$. Under the average construction price of 600 euro $/ \mathrm{m}^{2}$, the price of the works is estimated to be approximately 300 000 euro.

The difference in major construction costs between a diamond-type junction and at-grade intersection would be approximately 600000 euro. This difference for three junctions would be approximately 1.8 million euro in total.

The average area for the proposed intersections is approximately $10000 \mathrm{~m}^{2}$. The average area for the planned diamond-type junction is approximately 20,000 $\mathrm{m}^{2}$. The difference is $10,000 \mathrm{~m}^{2}$. When this difference in area is multiplied by a land purchase market price it follows that the difference in construction junction for three diamond interchanges is 3.3 million euro.

So, the variant with grade-separated junctions will result in the following increase of costs in relation to Variant I:
1. Construction costs
$1,800,000.00$
2. Required area
$3,300,000.00$
TOTAL :
5,100,000.00 EURO

Total difference in major initial costs is estimated to be 5.1 million euro. This difference is the sum of greater expenditure entailed for the variant with gradeseparated junctions.

\subsection{Comparison of benefits in the design period (fuel consumption and time losses)}

Fuel consumption has been calculated based on projected traffic flow on the major road at the end of the design period (2024) which differs from the present traffic flow by only 3\%. Excluded in the calculation is incremental increase in traffic flows which is likely to occur until sections of the Adriatic Highway are put into operation.

According to the methodology applied in the Synchro program, the fuel consumption on the subject section in a peak hour was 1,732 liters. The terms used in the Synchro and TRANSYT 7-F programs were used in the computation of fuel consumption. Accordingly, the fuel consumption does not depend only on the total length of travel of all vehicles but also on total delays of all vehicles and the total number of stops.

The fuel consumption computed for the variant with grade-separated junctions was 1,3231 . This means that due to traffic signal caused deceleration, 
stops and acceleration, an increase in fuel consumption of 409 liters or 30\% in a peak hour is likely to occur in relation to the fuel consumption over the major road with continuous traffic flows. This increase is equal to approximately 4000 1/day i.e. approximately 4300 euro.

When applied to annual fuel consumption, this increase is equal to 1570000 euro greater expenditure for fuel in relation to grade-separated junctions, or 31 400000 euro greater expenditure at the end of the design period.

Mention should be made that pollution i.e. quantity of exhaust gases, will be greater by at least $30 \%$ according a simplified assumption that quantity of exhaust gases linearly increases with fuel consumption. A negative impact of environmental pollution has not been computed in terms of expenditure.

According to the computations, delays or time losses of all vehicles on the reference road section in a peak hour is equal to 18.27 hours or approximately 183 hours daily.

In order to express the losses in expenditures the following formula has been applied: the average gross salary in Croatia is divided by an average number of working hours in a month, which results in more than 4 euro/hour.

The expenditure of 4 euro/hour gives a daily loss of 730 euro or an annual loss of 266450 euro. Loss in the design period amounts to 5329000 euro.

In this benefit-related evaluation, the estimates for depreciation costs of vehicles caused by interruptions in the traffic flow, such as breaking, shifting gears, restarting, etc. are not included.

So, in the 20-year design period, Variant I with traffic signal controlled would produce the following increased costs in relation to Variant II:
1. Fuel consumption
31400000
2. Time losses
5329000
TOTAL:
36729000 EURO

\subsection{Difference in costs and benefits between the variants}

As the initial costs as well as benefits over the design period are evaluated under the same methodology, for the purpose of comparing the alternatives it has been required that user costs assessed over 20 years be discounted back to a present value year to obtain the net present value for the scheme. The method applied involves the assumptions on invariability of a discount rate and equality in the incurred costs in each of the analyzed 20 years. The latter assumption is based upon the fact that projected traffic in the year 2024 shall not be exceeded by more than $3 \%$ in relation to the existing traffic. As the fuel costs and time losses occur in the first year of the road use, and the difference between the existing and projected traffic can be disregarded, it has been assumed that losses will be identical in each year of the design period. The incremental increase of traffic flows in the initial years before putting the Adriatic Highway into operation was not taken into account, nor was new traffic flow.

As shown above, Variant I, traffic signal controlled intersections, will produce approximately 36.7 million euro higher costs over a 20 -year period in relation to the alternative solution. By applying an $8 \%$ discount rate and assuming identical 
annual costs of 1.835 million euro over a 20 -year period a net present value of 18 million euro for fuel consumption and time losses will be obtained.

The variant with grade-separated would produce a cost increase of approximately 5 million euros in relation to Variant I.

Therefore, the total difference in construction costs and operating costs over a 20 year-period expressed as net present value is estimated to be approximately 13 million euro in favor of the variant with grade-separated junctions.

In the above computations are excluded many losses, e.g. the increased wear and tear of vehicles, environmental pollution-related costs, traffic accident costs, etc. Also, the incurred costs on minor approaches are not taken into account. Such costs would additionally increase the difference in costs, i.e. would favor the variant with grade-separated junctions.

However, these results of economic assessment over the assumed relatively short 20-year period indicate that the variant with grade-separated junctions would produce a savings of approximately 13 million euro.

\section{Conclusion}

The results of comparative cost benefit analysis for two variants showed that the preferred solution is a road with continuous traffic flow passing over gradeseparated facilities. This solution is not only advantageous in terms of quality, but also in considerable cost savings over the 20-year design period. Although excluded in the computations are many losses (increased tear of vehicles, environmental pollution, traffic accidents, minor vehicle costs, etc.) which are considerably lower in the variant with grade-separated junctions, the preferred option is likely to result with lower expenditure over 13 million euro in a period of 20 years.

\section{References}

[1] Croatian government. Program of construction and maintenance of Croatian public roads. Zagreb, 2000.

[2] Hrvatske ceste d.o.o. Traffic Counts on the Croatian Roads, Zagreb, 2002.

[3] Prometis, Physical Planning with Traffic Analysis for State Road 8 Solin Plano section Study, Zagreb 2001.

[4] Institut građevinarstva Hrvatske. Preliminary Design for the D8 Plano - K. Sućurac Road Reconstruction, Split, 1992.

[5] Građevinski fakultet Sveučilišta u Splitu, Traffic Study of City of Split, Split 1994.

[6] Florida Department of Transportation. Quality/Level of Service Handbook and LOSPLAN software, 2002.

[7] Transportation Research Bord. Highway Capacity Manual (HCM2000) Washington, DC,2000.

[8] Synchro 5, Traffic signal coordination Software - Demonstration version, Trafficware 